\title{
Por un materialismo fónico
}

GABRIELA MILONE Universidad Nacional de Córdoba - CONICET, Argentina / gabymilone@gmail.com

\section{Resumen}

En el presente trabajo postularemos la categoría de «materialismo fónico», reflexionando desde el pasaje de la voz a la letra (Agamben). Localizaremos diversas poéticas argentinas y latinoamericanas, donde se proyectan escenas singulares de escritura de la voz; escenas que a su vez abren un campo de indagación crítica no idiomática sino de juegos fónicos, de sonidos que coexisten en diversas temporalidades y espacialidades y sobreviven a las normalizaciones de las gramáticas y a los dictados de la retórica. Desde la idea de Barthes del «susurro de la lengua» (esa utopía de una lengua en la formación de un inmenso tejido sonoro donde el significante fónico y vocal no elimina completamente el «sentido» sino que lo aleja como un espejismo) leeremos en diversas escrituras poéticas (Juan Carlos Bustriazo Ortiz, Oscar del Barco, Andrés Ajens, Mauro Césari) la acentuación del nivel fónico por sobre el semántico, tarea que nos permitirá configurar una singular cartografía de lo que denominaremos «ficciones fónicas» donde es posible vislumbrar un campo de fuerzas fónicas en acto en ejercicios vocales donde se escribe la materia de la voz.

Palabras clave: voz / lengua / letra / sonido / escritura

\section{For a phonic materialism}

Abstract

The present work proposes the category of «phonic materialism", from the passage of the voice to the letter (Agamben). We will analyze the writing of the voice in argentian and latin american poetics: phonic games, sounds that coexist in different temporalities and spatialities, outside the rules of grammar and rhetoric. From the idea of Barthes of the "rustle of the language» (that utopia of a language where the phonic significant does not eliminate the "sense» but postulates it as a mirage) we will read in the writings of Juan Carlos Bustriazo Ortiz, Oscar del Barco, Andrés Ajens, Mauro Césari, the accentuation of the phonic level over the semantic one, from «phonic fictions». We will configure a cartography of phonic forces in the act of vocal exercises that write the matter of the voice.

Key words: voice / language / letter / sound / writing

Recibido: 1/3/2020. Aceptado: 20/4/2020

Para citar este artículo: Milone, G. (2020). Por un materialismo fónico. El taco en la brea, 11 (diciembremayo), 82-91. Santa Fe, Argentina: UNL. DOI: 10.14409/tb.vii11.9156 
Nos proponemos en estas páginas postular la categoría de «materialismo fónico» en escrituras poéticas argentinas y latinoamericanas, pensando específicamente en el pasaje de la voz a la letra. Proponemos localizar diversas poéticas que escenifican la escritura de una voz abriendo un vasto y enriquecedor campo de indagación crítica no idiomática sino de juegos fónicos, de sonidos que coexisten en diversas temporalidades y espacialidades y sobreviven a las normalizaciones de las gramáticas y a los dictados de la retórica. Este movimiento se hace eco, de cierta manera, de una idea de Phillip Sollers sobre Francis Ponge. Nos referimos a la noción de «materialismo semántico» con la que Sollers se refiere al método creativo de Ponge, materialismo donde las palabras y las cosas buscan tener la misma densidad material. A lo que se suma otra reverberancia: la idea de la «lectura exploratoria» que Nicolás Rosa sostenía en «Lecturas impropias», donde concretamente se propone un tipo de lectura del «texto poético» que se produzca en la deriva de significantes, en una «deltificación» (73) que no atienda sino que atente contra el anquilosamiento de los significados. Sin embargo, es la recuperación de una noción de Roland Barthes la clave de nuestro trabajo. Nos referimos al «susurro de la lengua» (1987:99-110), esa dimensión sonora que si se la piensa desde el habla se configura como balbuceo, mientras que si se la intenta postular como escritura pareciera que se asemeja a la total inarticulación. Para Barthes, el susurro de la lengua implica postular una Utopía, esa que se diagrama en la formación de un inmenso tejido sonoro donde el significante fónico y vocal no elimina completamente el «sentido» sino que lo aleja como un espejismo. El sentido se figura como en bloque, espejeando a lo lejos; mientras que la lengua, en su susurro, se despliega en «ejercicios vocales» donde el trabajo de la voz se exime del sentido, lo niega en cuanto totalidad, lo experimenta como algo lejano y engañoso: un espejismo.

La lengua susurrante es así una utopía abierta entre la voz y la letra: un umbral entre la voz balbuceante y la escritura entrecortada. Es un ejercicio vocal cuya extensión fónica alcanza la materia del lenguaje no como sentido ni como negación de sentido, sino como volumen sonoro. En el espesor de la lengua, su susurro se abre como un campo fónico inexplorado y delicado: no es simple negación del sentido en la mera afirmación del sonido por sí mismo. Significado y significante no se anulan ni se superponen sino que diagraman una relación otra, y es allí donde buscamos pensar ese encuentro (o acaso desencuentro) entre los dos grandes bloques materiales de la lengua: la fonía y la grafía Y pensarlo menos para profundizar sus heterogeneidades que para habilitar un hacer (poiesis) en sus intersticios, en las grietas donde lo sonoro y lo gráfico invitan a la imaginación del entrecruzamiento de sus haces.

Si bien recordamos la alerta derridiana (Derrida, 1970:59) de que el «fonema es inimaginable en sí mismo», buscamos abrir una zona donde sea posible la exposición de la lengua, donde se abra ese «ameno fonema» del que hablaba Filloy (54) en su Karcino: fonema dúctil, que traza la apertura de la voz a la letra. En ese sentido, pensamos menos en la invención de otra lengua (o de una lengua otra, como si tal cosa fuera posible) que en la mostración de la materia de la lengua; vale decir, que nos interesa menos una teoría que parta de lo irreconciliable de la fonía con la grafía que de la posibilidad de un hacer poético con las supervivencias fónicas de la voz en la letra. El pliegue que forma lo fónico se muestra como un escenario privilegiado: ni sonido "puro» ni «pura» invención gráfica, vale decir, ni simple masa amorfa de lo sonoro ni fonetización formalizada en la letra. Ni físico ni fonético, pensamos lo fónico como un intersticio material donde susurra la lengua (poética) significante sin significar, más que como espejismo. Hablamos de materia fónica 
así como Starobinski (cf. 22, 58, 129) lo hace en el estudio de los anagramas de Saussure: materia prima vocálica y consonántica, trama o malla fónica hecha de sonidos con letras y de letras con sonidos donde no es posible distinguir qué pertenece estrictamente a la fonía y qué a la grafía, qué a lo fonético del significante y qué a lo fonetizado del significado. Más que como heterogeneidades o desemejanzas radicales (cf. Derrida, 1970:71), decíamos, buscamos imaginar un pliegue fónico donde la lengua expone su materia a las variaciones, las latencias, las «invenciones interpretativas» (Saussure en Starobinski:91). Allí, en ese campo, los ejercicios de la voz (en la poesía) se debaten entre la boca y la letra, y en su pliegue radica la utopía de la lengua susurrante para Barthes.

A los fines de indagar el materialismo fónico en poéticas que exponen lo que podría llamarse apariencias de lengua (en el juego del «como si» donde — tal como sostenía Barthes-el significado no desaparece sino que funciona como un espejismo, ni lejos ni cerca, ni antes ni después, sino en la superficie reverberante del sonido), buscamos abrir una vía de reflexión por medio de la ficción y así postular la idea de ficciones fónicas en la escritura poética. Ahí donde Barthes habla de la utopía del susurro de la lengua, nos gustaría pensar desde la idea de ficción teórica de H. Libertella. Esta categoría, por demás sugerente para nuestro trabajo, la hallamos así enunciada en el libro Ensayos o pruebas sobre una red hermética (1990:90); pero es particularmente en un pasaje de Zettel donde vemos su amplificación y advertimos sus alcances:

Tanto la teoría nace por la determinación previa de un modo de cálculo que propicia el nacimiento de un nuevo objeto como la ficción es el modo de calcular un imaginario que va a dar nacimiento a un proceso artístico, lleve o no una nueva «obra de arte». (¿De donde teoría y ficción, enemigas, serían acaso lo mismo?). (2008:27)

Ficción y teoría, en tanto cálculos que propician el surgimiento de un elemento nuevo, no serían heterogéneas ni inconciliables. Es más, entre ambos cálculos habría un espacio posible, una zona novedosa o no pre-supuesta, lugar donde ficción es teoría y teoría es ficción, o sea: ficción teórica. Por qué no leer, dice en otro pasaje Libertella, un texto puramente teórico como poema o un poema como prosa y así asistir a la conversión de la teoría en ficción y viceversa. Este método sin dudas tiene sus resonancias en lo que R. Barthes (2005:46) exponía al inicio de su seminario sobre el vivir juntos: que solo hablaría de método si se lo hiciera mallarmeanamente, esto es, en tanto ficción. $O$ lo que es lo mismo para el autor: en tanto lenguaje que se refleja en el lenguaje (Barthes se refiere, sin citar, al texto «Notas sobre el lenguaje» de Mallarmé). No debemos olvidar que Barthes hace referencia a esta cuestión especialmente en el momento de la apertura de su seminario, lugar que concibe como la posibilidad de soñar una investigación. Y en este espacio es necesario trazar un camino, un método; o lo que es lo mismo: inaugurar una ficción (un «fantasma»). Investigar es teorizar una ficción, seguir una insistencia, explorar una palabra, sobreimprimir deseo a ciencia. De este modo, investigar no difiere mucho de inventar, de hacer venir determinados vestigios y así inaugurar una zona de exploración singular. Sin embargo, Derrida (2017:39) nos advierte del equívoco de pensar la invención como creación ex nihilo. La compleja economía de la invención hace venir conjuntamente la imaginación y la técnica, la fábula y el método. Se inventan máquinas, se inventan relatos. Y sin embargo, esa compleja red lexical que el término «invención» traza (donde cada lengua podrá reconocer su parte del término «venir») no habilita a postular un «invento» como algo venido o creado de la nada. Toda invención será una in(ter)vención (35), un entre teoría y 
ficción, un entre imaginar y hacer, un entre lo venido y lo por venir. Toda invención es una nueva configuración, una venida otra de lo inter-venido: una in-vención.

Nuestro movimiento zigzagueante que va desde la ficción teórica libertelliana, pasando por la investigación ficcional de Barthes, hasta la in(ter)vención derridiana, tiene un propósito clave: disponer para nuestro trabajo de esa categoría sumamente abierta, plástica, sugerente de Libertella, para abrir una posibilidad de reflexión sobre nuestra materia, con un modo más cercano a la invención que al análisis. Esto es, bregar por la posibilidad de in(ter)venir una materia (poética), zona donde es posible hacer venir ficciones teóricas que amplifiquen sus elementos. Que amplifiquen, justamente, ese significante fónico que pide categorías para ser pensado (esto es: ficcionado teóricamente, inventado). Inventar, intervenir, hacer venir juntas ficción y teoría: tal es el cometido (¿metodológico?) que, a la escucha de quienes supieron hacer ese camino (método), se propone nuestro trabajo.

\section{II}

Para Libertella (1990:76), los extremos de la lengua serían el vagido y el grafismo, el sonido insignificante y la letra. De este modo, la fonía y la grafía exponen un movimiento de lengua que va de un extremo a otro en una misma f(r)icción, ahí donde la lengua se ficciona, se fricciona, se flexiona, no para desaparecer ni para negarse, sino para mostrarse en un campo fónico en acto. En este campo, la escritura poética puede ser pensada menos como un mero juego formal y/o experimental de des-acomodación fonética (más o menos vanguardista) que como figura de una lengua que ficciona sus sonidos, al ras, susurrando ante los espejismos de sentido. Es así como el campo que buscamos explorar no sería inter-lenguas sino exclusivamente intra-fónico, vale decir: escenas donde la escritura de una voz problematiza la letra en juegos fónicos que permiten armar así menos un sistema de influencias que un mapa de (más de) una lengua poética, de ejercicios vocales donde se escribe la materia fónica de la voz.

G. Agamben, en «El fuego y el relato» expone (una vez más) su idea sobre la escritura poética, afirmando que la misma «no dice sólo lo que dice sino que dice también el hecho de que lo está diciendo, la potencia y la impotencia de decirlo» (2016b:44). Es así como en la poesía se da la suspensión y la exposición de la lengua: al suspender «lo que se dice» (el espejismo del significado de Barthes, quizá), expone «que lo dice»; desactiva el contenido de lo que dice para, en ese mismo movimiento, abrir la escena de la contemplación de la lengua en su potencia de no (decir). Es la poesía para Agamben justamente el «modelo por excelencia» del «girar en el vacío» de la inoperosidad: «¿qué es la poesía sino una operación en el lenguaje que desactiva y vuelve inoperosas las funciones comunicativas e informativas para abrirlas a un nuevo, posible uso?» (49). Esta idea, que ya había sido expuesta en varias ocasiones por el pensador italiano (en ciertos pasajes de El final del poema y de Idea de la prosa, por caso), presenta en este texto un elemento nuevo, una mención nunca antes realizada: nombra a Trilce de César Vallejo como ejemplo de la contemplación de la lengua española. Para el italiano, menciona a Dante; para el provenzal, a Arnaut Daniel; para el francés, a Rimbaud; para el alemán, a Trakl y Hörlderlin. Y para el español, solo a Vallejo (y especialmente a su inclasificable Trilce). Si extremamos la hipótesis, podemos pensar que la contemplación de la lengua española se daría justamente fuera de España, acaso en la exposición de una excepción y en la efectiva suspensión de una gramática, en la singularidad de un nombre —ese vórtice en los que «la tensión semántica y comunicativa se abisma a sí misma» 
(53) — nombre enigmático y magnético — Trilce — del que solo se tejen hipótesis (espejismos) en torno a su significado.

A partir de estas reflexiones sobre la idea de susurro y espejismo de Barthes como así también de contemplación y suspensión de la lengua de Agamben, quisiéramos diagramar una posible ficción teórico-fónica que siga la estridencia de una voz sonando en la letra del poema, que contemple un tipo de escritura donde la lengua se encuentra ficcionada, flexionada. Buscamos en suma abrir el campo de las ficciones fónicas en escrituras contemporáneas como las de Juan Carlos Bustriazo Ortiz, Oscar del Barco, Andrés Ajens, Mauro Césari, entre otros. Nos interesa particularmente la disparidad de estas voces y sus escrituras para explorar ese encuentro de sonidos que exponen el trabajo con/de la lengua que, al atentar contra las sistematizaciones de la crítica, habilita un espacio otro (¿acaso una utopía?) para las reflexiones sobre la voz y la letra. En la materia sonora de la lengua, estas escrituras ficcionan fónicamente en el medio de las palabras, flexionan la voz en la letra y viceversa, gestan la posibilidad de moldear (fingere: figura y ficción) un materialismo fónico que no busca leer los sonidos en el derecho de la historia de las lenguas ni en el revés de la mirada comparativa. $\mathrm{Ni}$ al derecho ni al revés sino al ras de los sonidos, en ese encuentro potencial donde este materialismo busca marcar un camino para problematizar la voz en la literalidad de la letra.

\section{III}

Las ficciones fónicas que postulamos en este trabajo expondrán cuatro escenas singulares donde se despliega el inmenso tejido sonoro de la lengua: la voz enterrada, la voz estallada, la voz inesperada, la voz entreverada.

Esta posible cartografía comienza en un punto; uno que, aunque inicial, es perfectamente aleatorio. Nos referimos a la escritura de Juan Carlos Bustriazo Ortiz (La Pampa, 1929-2010), y especialmente a los poemas de Las Yescas. Canciones del enterrado (incluido en Herejía bermeja, 2008). Aquí situamos nuestra primera escena, la de la voz enterrada. No una voz muerta, apagada, oculta, encriptada; sino una voz sumergida, inmersa, ensimismada. Porque en esta escritura poética asistimos a una ficción fónica de la lengua en la lengua, entre líneas de sonidos. En un movimiento de re-pliegue fónico, aquí se expone un juego especial: insiste en la sufijación en «ura» para palabras que no sufijan así (saladura, paridura, agridura, truenura, temblura, luegura, alegrura). En este juego de desacomodar las partes, lo que observamos es que estos sonidos, aunque no pertenecen a esas palabras, sí pertenecen a la lengua. En este sentido, vemos el movimiento de una lengua que se ensimisma y expone el ejercicio vocal de un susurro trabajando sobre el fondo del espejismo del sentido. Leamos un fragmento de uno de los poemas del libro mencionado, titulado — como la mayoría de los poemas del libro— «Bordona»:

...llagaluna me tocas saladura...

(...torbellino de flor batalla verde dónde está la tan mía tan tri-

gueña la que ardía cuajada de ponientes la salida del humus de mi yesca oh cencerros bermejos celesteen pariduras del agua resplandezcan dónde estás abejura de la muerte agridura del beso cueva trémula enlunada de sal y taza verde anca dulce galope de la pena o galope

(...)

(Bustriazo Ortiz:49) 
Como decíamos, es en este juego especial de sufijaciones donde leemos el pliegue fónico de la lengua ensimismada, lengua que aleja el sentido como espejismo; donde los sonidos ficcionan las palabras pero no las deforman, las friccionan en un campo fónico en acto. Allí el significado no desaparece sino que está modelado, figurado, acaso tal como pensaba Deleuze (cf.) lo figural de Bacon, donde no se producía la destrucción de la figura sino el borramiento de los bordes, la suspensión del relato. Así como una figura que se desprende del fondo representativo, la sufijación bustraziana se despega del bloque significativo de la lengua y expone ese espesor del significante fónico del que hablaba Barthes. Al desacomodar las partes, el sonido se extraña y se espesa en la escritura que lo exhibe, y el nivel semántico se desquicia y espejea. Más que un sufijo dando cuenta de una calidad propia o de un resultado, en el sonido «ura» se muestra el trayecto de un haz fónico que va de la boca entrecerrada de la «u» hacia la apertura sonora de la «a». El movimiento lo marca la letra «"» (cf. Genette:30), en cuyo sonido se da cuenta de la rosca que la lengua hace en su plieguedespliegue fónico. En el recorrido de lo cerrado a lo abierto, la voz escrita de esta ficción fónica interviene la materia disponible del lenguaje y así juega a las apariencias de una lengua inventada.

El siguiente punto de la cartografía lo situamos en la escritura poética de Oscar del Barco (Córdoba, 1928), la cual despliega la escena de la voz estallada. Es clave mencionar que en las propias reflexiones de del Barco nos encontramos concretamente con la idea de espejismo. En un texto titulado «Golpe ciego», se afirma:

(...) uno no habla sino que está el habla, ni llora sino que hay lágrimas, ni odia sino que hay el odio, ni camina, ni ama, ni vive, ni muere. El espejismo está metido hasta en los huesos, y de allí hay que sacarlo. (2010a:186)

El espejismo (del Sentido) para del Barco es pura superficie (pero no obstante actúa de fondo y en el fondo) y la mayor cuestión radica en cómo no caer en la trampa de creer que es posible salirse de su lógica. De este modo, la figura del espejismo conlleva una doble valencia: hay espejismos, creemos que accedemos a un significado determinado pero no existe más que como una ilusión o (nietzscheanamente) como mentira; no hay más que espejismos, y el reconocimiento de esto nos protege de su propia trampa al mismo tiempo que habilita una zona de ficción de la lengua donde el significando queda alejado y la superficie fónica adquiere un espesor singular. De aquí es que podamos leer en la escritura poética de del Barco una voz estallada, un grito al ras de la lengua, un alarido apenas audible, un susurro desesperado. Y su juego será el de los pronombres, ahí donde la lengua se indetermina en el espacio y en el tiempo. Los pro-nombres parecen ser el elemento clave en esta escritura, ya que juegan en esa doble valencia del espejismo: no frenan el mecanismo (lo cual se sabe imposible) sino que lo desquician. Leemos esta cuestión especialmente en su libro partituras (2010b): ${ }^{2}$

palabra

dice

no

quién sabe

de quién

o qué 


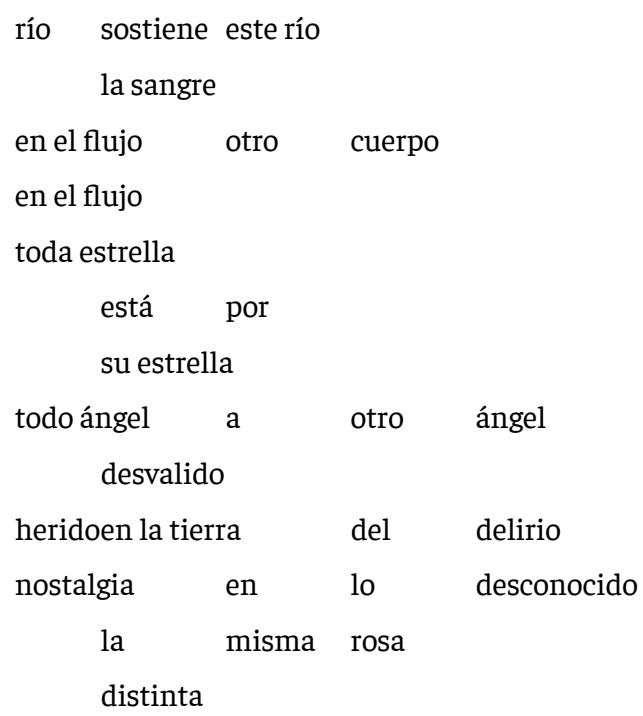

El estallido mallarmeano del verso, rompiendo la linealidad de la escritura y en la diagramación de una espacialidad otra, sugiere al mismo tiempo la configuración de otro tipo de volumen o espesor material de las palabras. Como si en esta configuración estallada del verso, las palabras expusieran su volumen sonoro; y en ese movimiento, divisaran el sentido al ras, como un espejismo. A su vez, nos referimos especialmente al libro partituras dado que allí la escritura poética expone una intriga clave: ¿cómo se escribe una voz en la partitura, cómo suena la voz escrita? No se trata de una cuestión que pueda plantearse (vía Derrida) por el estudio de la fonetización de la voz, sino más bien es un interrogante que busca quedarse en el misterio de la voz que habla cuando a su vez se escribe.

Enlazamos ahora con el punto siguiente, con la escena de la voz inesperada en la escritura de Mauro Cesari (Entre Ríos, 1977); y especialmente pensamos en un texto: Una tarde en ciudad Ganglio (2014). Allí, la escritura sondea el enigma del habla a través de la indagación de los órganos de fonación del lenguaje, insistiendo en la pregunta por los nervios, envolturas, enervaciones que van del mero sonido a la lengua articulada, en su trayecto de la voz a la letra. Del vagido al grafismo, la insistencia en el sonido, la piel, los orificios, las mucosas, las cavidades, las glándulas, las convexidades, los cartílagos, vale decir, en todos los conocimientos producidos en torno a los elementos que participan en la fonación, no logran despejar la incógnita del habla. Agamben, en «Experimentum vocis» (2017:24 y 25), propone una hipótesis (una ficción teórica, podríamos decir) sobre este enigma, y sostiene que eso que imaginamos como el origen del lenguaje no sería otro momento que el de la toma de conciencia del habla, momento en el que la lengua se vuelve objeto de estudio. Así sería como, luego de que la lengua fuera expulsada hacia el exterior como objeto y reinscripta en la voz a través de los fonemas y las letras, el análisis de la lengua coincidiría con la articulación de la voz. Y aquí, la noción de letra (que Agamben refiere a Aristóteles) es la clave. Porque el problema no sería (solamente) de dónde viene la voz sino cómo esta se vuelve articulable, cómo se hace parte del proceso del lenguaje en la medida en que se vuelve escribible. Para Agamben, en la cuestión de la voz que se escribe radica toda la situación del lenguaje occidental, su mito y su potencia.

En la Ciudad Ganglio resulta como si no hubiera nada de la lengua que no se hubiera vuelto externa, extraña, inesperada. El habla yace y se yergue en las enervaciones de la cavidad bucal, 
nervios que se alzan articulando algo más que el mero sonido: el misterio de su repetición, la magia de su umbral. Leemos al inicio del libro:

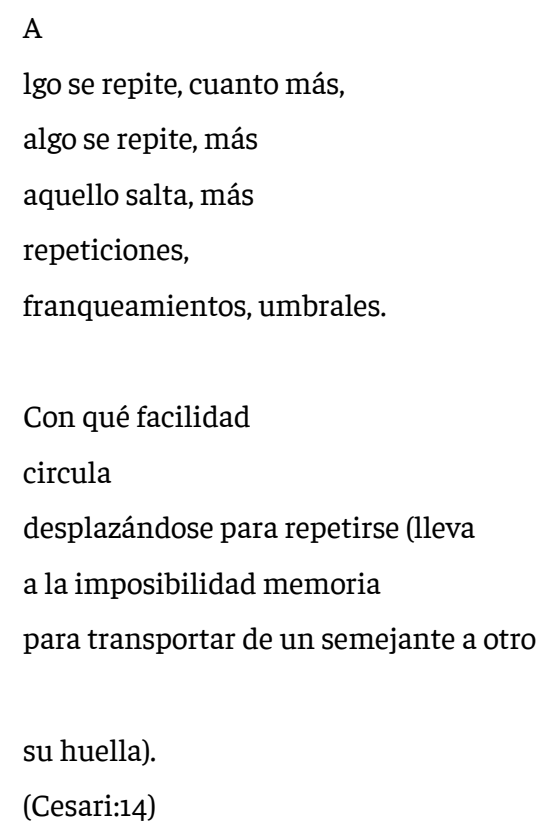

La «A» del inicio, en letra capital, es la señal de la apertura: la boca se abre, el libro se inicia, esta ficción fónica se inaugura. La repetición es el signo de lo inesperado, del azar de las insistencias. Es en ese «algo» que «se repite» que se despliegan los juegos verbales y visibles del habla poética, en la escenificación de la materia enigmática del lenguaje cuando explora, a contraluz de los espejismos del sentido, la zona extraña de sonidos que se abren en la huella de la lengua.

De la cartografía posible de ficciones fónicas, el último punto lo situamos en la escritura de Andrés Ajens (Concepción, Chile, 1961). También aquí nos referimos particularmente a un libro: $A E$ (2015) y a una escena: la de la voz entreverada. Asistimos a una ficción fónica entramada, precisamente, como un tejido: ya sea de entre-lenguas (aymará, quechua, alemán, inglés, portugués), como así también de entre-letras (diversos y abundantes tipos y marcas tipográficas). Al inicio, en la letra que da nombre a este libro, vemos un anacrónico trazo superpuesto de dos vocales; pero la boca debe pronunciar solo una: se teje en un entrevero de A y E, un entre-cerrado vocálico de dos aperturas de boca. En el tejido de voces y de letras del lenguaje, esta f(r)icción se obstina en un movimiento de pliegues de palabras y re-pliegues de sonidos, un trenzado de susurros y balbuceos en diversas lenguas que van haciendo «hordas de escritura» (Ajens:53) para espejear el sentido y espesar el tejido sonoro de la lengua. Leamos un poema de la sección «Aquende allende» del libro:

Ohohohoh

empuja la palabra

dentro de la boca - fuera : em

pújala

hasta donde tal 


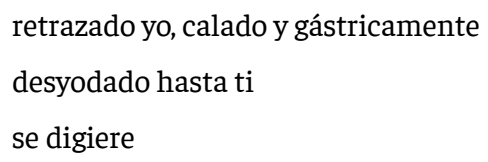

en el transflujo arriba un $\mathrm{r}$

esto b o qu i a bi e r t o, saliva

(Ajens:50)

Tal como la apertura de la «A» de la Ciudad Ganglio, aquí es la «O» ese «resto boquiabierto» que expone su secreción fónica y hace de su ficción de lengua una continua mostración de la materia de la que está hecha. En ese resto vocal y bucal, el sonido se escribe en el dibujo de la apertura de la boca, cuestión que ha sido largamente estudiada, por caso, por Genette (71 y ss.) bajo su categoría de «mimografismos». El estudio de esta cuestión agrega un pliegue más a la reflexión sobre la articulación de la voz en la letra, en la medida en que postula la posibilidad de observar en cada letra un análogo visual de un fonema. Así, se podría soñar con una mímesis gráfica y Genette lo piensa particularmente en dos tipos de alfabetos miméticos: aquellos que acentúan la representación gráfica del aspecto acústico de las palabras y aquellos que enfatizan el aspecto articulatorio de la fonación. En esta segunda línea, se piensa la escritura de las vocales «A» $\mathrm{y}$ «O» en tanto mímesis de la forma que la boca adopta en la articulación de ese sonido. De la voz a la letra, ese resto boquiabierto que expone $A E$ juega a entreverar los hilos fónicos del inmenso tejido sonoro de la lengua del que hablaba Barthes que aquí asume la figura del aguayo, fonemas tejidos provenientes de diversas lenguas, muchos tiempos, múltiples espacios. Y así, cerrando esta posible y siempre abierta cartografía de ficciones fónicas, muestra el mismo movimiento que observamos en las escrituras poéticas aquí convocadas: ese despliegue material donde la voz escrita se enfrenta a la potencia incalculable de lo sonoro de la lengua; y en sus diversos ejercicios (el juego de las sufijaciones, los pronombres, las repeticiones, los entretejidos) diagrama un (aún) incalculable campo de fuerzas fónicas en acto. Es así como el gesto del materialismo fónico, insistimos, será siempre el de explorar ese volumen sonoro, en cuya espesura incalculable la fonía y la grafía invitan a la in(ter) vención de su ficción.

\section{Notas}

1 Como se sabe, la obra poética de Bustriazo Ortiz está en buena parte aún inédita y su publicación acarrea problemas de diversa índole. Aclaramos que citamos desde la edición de Herejía bermeja, volumen que contiene buena parte la obra poética de este autor, publicada en 2008 por la editorial Ediciones en Danza de Buenos Aires y prologada por Cristian Aliaga. Aquí puede leerse específicamente la producción que abarca desde

1969 a 1977, además de algunos poemas sueltos (de 2007), una entrevista y algunos estudios y recensión de notas críticas sobre su obra. En lo que respecta a Las yescas. Canciones del enterrado, una nota al pie aclara: «Inédito. Esta obra incluye treinta y ocho poemas titulados alternativamente “Canción” y “Bordona”» (35). 2 Intencionalmente la edición de partituras no posee números de páginas. 


\section{Referencias bibliográficas}

Agamben, G. (1989). Idea de la prosa. Barcelona: Península.

- (2016a). El final del poema: estudios de poética y literatura. Buenos Aires: Adriana Hidalgo.

(2016b). El fuego y el relato. México: Sexto Piso.

(2017). Experimentum vocis. ¿Qué es la filosofía? Buenos Aires: Adriana Hidalgo, 9-47.

Ajens, A. (2015). AE. Santiago de Chile: Das Capital.

Barthes, R. (1987). El susurro del lenguaje. Más allá de la palabra y de la escritura. Barcelona: Paidós.

(2005). Cómo vivir juntos. Simulaciones novelescas de algunos espacios cotidianos. Buenos Aires: Siglo XXI.

Bustriazo Ortiz, J.C. (2008). Las yescas. Canciones del enterrado en Herejía bermeja. Buenos Aires: Ediciones en Danza.

Césari, M. (2014). Una tarde en Ciudad Ganglio. Bahía Blanca: Vox.

Del Barco, O. (2010a). «Golpe ciego». Alternativas de lo posthumano. Buenos Aires: Caja Negra.

(2010b). patituras. Buenos Aires: Activo Puente.

Deleuze, G. (2013). Francis Bacon. La lógica de la sensación. Madrid: Arena Libros.

Derrida, J. (1970). De la gramatología. México: Fondo de Cultura Económica.

(2017). Psiché. Invención del otro. Psiché. Invenciones del otro. Buenos Aires: La cebra, 13-66.

Filloy, J. (2013). Karcino. Tratado de Palindromía. Buenos Aires: Adriana Hidalgo.

Genette, G. (1976). Mimologiques. Voyage en Cratylie. Paris: Édition du Seuil.

Libertella, H. (1990). Ensayos o pruebas sobre una red hermética. Buenos Aires: Grupo Editor Latinoamericano. (2008). Zettel. Buenos Aires: Letranómada.

Ponge, F. y Sollers, Ph. (1970). Entretiens de Francis Ponge avec Philippe Sollers. Paris: Edition du Seuil.

Rosa, N. (1997). La lengua del ausente. Buenos Aires: Biblos.

Starobinski, J. (1996). Las palabras bajo las palabras. La teoría de los anagramas de Ferdinand de Saussure.

Barcelona: Gedisa. 